\title{
Factors Influencing EFL Learners' Attitudes toward English Varieties
}

\author{
Arifumi Saito \\ University of Aizu, Japan \\ arifumi.saito@gmail.com
}

DOI: http://doi.org/ 10.36892/ijlls.v3i1.623

$\begin{array}{ll}\text { Received: } & \text { Abstract } \\ \text { 13/06/2021 } & \text { This study explores how intercultural communication and the knowledge of } \\ \text { Accepted: } & \text { English as an International Language' (EIL) affect EFL learners' perception } \\ \text { and attitudes toward "non-native" English varieties. Since EIL encourages } & \text { non-native English speakers to use their own English with expressions } \\ & \text { reflecting their cultures and identities, introducing EIL in EFL classes is } \\ \text { Keywords: } & \text { expected to lead EFL learners to positively change their mindset for English } \\ \text { EFL, EIL, SLA, } & \text { varieties and enhance their confidence in their own English. In this research, } \\ \text { intercultural } & \text { Japanese and Chinese/Vietnamese college students were divided into two } \\ \text { communication, } & \text { groups and assigned different readings (EIL vs. non-EIL readings) before the } \\ \text { L2 speaking } & \text { discussion on English varieties. After the intercultural communication, } \\ \text { confidence } & \text { participants were asked to write about their ideas on EIL, and their reflective } \\ & \text { writings were qualitatively analyzed to examine how the knowledge of EIL } \\ & \text { would influence the students'attitudes toward English varieties. As a result, the } \\ & \text { Japanese students who did the EIL readings showed a positive attitude toward } \\ \text { "non-native" English varieties, including 'Japanese English'. In contrast, the } \\ \text { Chinese and Vietnamese students showed a negative attitude toward them } \\ \text { across the board even after learning about EIL. We aim to investigate the } \\ \text { reasons and backgrounds of the results including what makes the difference } \\ \text { between the Japanese and the Chinese/Vietnamese students. }\end{array}$

\section{INTRODUCTION}

Along with globalization, the number of English language users has been growing rapidly, and it has become an international language to connect people with diverse linguistic backgrounds and to be widely used in various communication modes (Ramos \& Gatcho, 2019). It had reached the point that the majority of users are not native speakers of English, and they have more opportunities to speak English with non-native speakers than native speakers (Kirkpatrick, 2007). In response, non-native speakers have formed their own English that is different from 'Standard English' in terms of linguistic and cultural aspects. In the literature, the emergence of English varieties has been acknowledged and discussed by many researchers who describe the varieties as World Englishes (Bolton, 2004; BruttGriffler, 2004; Crystal, 2003; Kachru, 1985, 1992; Kirkpatrick, 2007; McArthur, 2002). In line with it, some of them (Görlach, 1997; Jenkins, 2006) have argued the importance of introducing various English varieties in EFL education.

With the background, 'English as an International Language (EIL)' started being highlighted as the instrument to introduce English diversity (both native and non-native) into the EFL curriculum. EIL is a term created by Smith (1976) whose aim was to encourage EFL learners to accept their English varieties and gain ownership of English, which potentially leads to high L2 confidence and performance of the learners. Following the idea of Smith, many scholars (McKay, 2002, 2003a, 2012; Rose \& Montakantiwong, 2018; Saud, 2020; Sharifian, 2014; Zacharias, 2014) have claimed a paradigm- 
shifting in English teaching from EFL to EIL. In a similar vein, other EIL researchers (e.g., Nakamura, 2002; Lee, Nakamura \& Sadler, 2017) stressed the crucial role of EIL to develop L2 confidence in EFL education based on the outcome of their empirical research.

In the previous study (Saito, Heo \& Perkins, 2020), we explored how Japanese EFL learners at college develop their L2 confidence through EIL learning and intercultural communication with international students from expanding circle countries (China and Vietnam). Their L2 speaking confidence level was measured before and after the treatment, and it was found that Japanese EFL learners gained confidence in English speaking. In the current study, we focus on the qualitative analysis of their post-survey result which includes their attitudes toward different English varieties. The result indicates that there is a considerable difference in the perception and mindset for English varieties between the Japanese and international students. The aim of the present study is, therefore, to explore what causes the Japanese and international students to have different attitudes toward English varieties.

With the growing importance of English as a global communication tool, incorporating the idea of EIL in the EFL curriculum is expected to help EFL learners to accept their own English varieties and gain ownership of English, resulting in boosting the L2 confidence and motivation. Furthermore, it facilitates EFL learners' understanding of other cultures through interaction with other English varieties, which is truly demanded as the form of international communication in the global society. Thus, the current study will serve as a stepping stone to develop ideas and methodology for EIL education in EFL classrooms in the future.

\section{LITERATURE REVIEW}

\subsection{World Englishes}

As globalization progresses, World Englishes, i.e., English varieties, start being recognized nowadays. Traditionally, English varieties have been most commonly categorized into the three groups: English as a native language (ENL), English as a second language (ESL), and English as a foreign language (EFL). In this classification, ENL is spoken in countries where the majority of the people use English as their primary language (e.g., UK, US, Australia, Canada, and New Zealand). In contrast, ESL is spoken in countries where the majority of people use English as their important or official language (e.g., India, Singapore, Malaysia, and Philippines). Lastly, EFL is spoken in countries where the majority of people do not use English as a daily life language but study the language at school (e.g., Japan, China, Korea, and Indonesia).

Further, Kachru (1985) proposed a 'three circles' (pp.366-367) model to classify the English varieties into the following co-centric circles.

i. An inner circle: 'the traditional cultural and linguistic bases of English'

ii. An outer circle: 'institutionalized non-native varieties in the regions that have passed through extended periods of colonization.'

iii. An expanding circle: 'regions where the performance varieties of the language are used essentially in EFL contexts'

These circles represent "the type of spread, the patterns of acquisition, and the functional domains in which English is used across cultures and languages" (p.12). The inner circle represents countries in which English was spread during the first colonial disperse and acts as a first language, such as the USA, the UK, Canada, Australia, and New Zealand. On the contrary, the outer circle refers to countries where English was spread during the second colonial disperse and plays an important 'second language' role in a multilingual setting (Rajadurai, 2005). Many outer circle countries used to be colonized by the USA or the UK, such as Malaysia, India, Kenya, Singapore, and the Philippines. Lastly, the expanding circle presents countries where English has gained ground recently and is learned as a foreign language. Although the countries do not have historical experience of being colonized by the inner circle countries, English has been taught as a 'foreign' language as the most useful vehicle of international communication (White, 1997). For instance, Japan, China, Vietnam, and Poland can be counted as the expanding circle countries. The model not only presents the classification of Englishes but also marks that English is not only one but many, and Englishes in the inner circle are not necessarily better. As Kachru mentions, "English now has multicultural identities" (p.357). Though there are interrelations 
ENL/ESL/EFL model and the three-circles model, the latter refers to "the types of spread, the patterns of acquisition, and the functional allocation of English in diverse cultural contexts" (Jenkins, 2009).

McArthur (1998) classified them into two groups: native vs. nativized varieties. The former group includes British, American, and Australian English spoken by native speakers. The latter group includes Englishes developed by non-native speakers with the influx of English in their countries, which reflect the aspects of the local languages and cultures. Given the two categories, however, Kirkpatrick (2007) points out that it is difficult to define criteria for each type and poses a question of whether the distinction between native and nativized varieties of English is a valid one or not. According to him, even American and Australian English, which are counted as native varieties under the view of McArthur (1998), can be considered nativized varieties because they have been developed under the influence of British English and later became to reflect the features of local languages and cultures at the same time. Hence, he suggests that "the difference between varieties of English can be explained by the fact that they are all nativized" (p.7). Namely, all English varieties are considered what has been nativized at one point in time.

\subsection{Attitudes toward Nativized English Varieties by EFL Learners}

Nonetheless, many EFL learners do not show a positive attitude toward nativized English varieties, including their own. In Japan, for example, many empirical research projects (Hanamoto, 2008, 2010; Matsuda, 2003, 2009; Takahashi, 2012; Yoshikawa, 2005) were implemented to view EFL learners' attitudes toward English varieties. Looking at some of their reports, many Japanese EFL learners regard Japanese English as one of the low-status English varieties (Matsuda, 2003) and hold negative stereotypes about nativized varieties (Hanamoto, 2010). One of the reasons causing this tendency is that learners do not acknowledge English varieties in school settings; the target model in EFL education is American or British English (Matsuda, 2009; Yoshikawa, 2005). That is, English varieties to which they can be exposed are very much limited (Yamanaka, 2006). Such an EFL learning environment in school education naturally brings EFL learners the prejudice against other nativized varieties, forming the learners' stereotypes and negative attitudes toward those varieties.

Takahashi (2012) investigated Japanese college students' attitudes toward Japanese English compared to those toward American English and Chinese English in her empirical research. To measure the students' attitudes toward each English variety, Takahashi focused on two dimensions: status and solidarity. That is, how highly the English variety is recognized and how familiar the English variety is for the students.

For the status dimension, native variety (American English) was highly evaluated more than nativized varieties (Japanese and Chinese English). In many EFL contexts, 'Standard English' (American and British English) is highly valued and incorporated as the target model in Asian countries including Japan. Therefore, such EFL educational environment naturally brings Japanese EFL learners positive and negative stereotypes toward native and nativized varieties, respectively. Some researchers (i.e., Hanamoto, 2008; Matsuda, 2003; McKenzie, 2004) reported that Japanese EFL learners showed positive attitudes toward native varieties (American or British English) while negative attitudes toward nativized varieties including Japanese English in terms of status value. In view of the background and research results, therefore, it is understandable that the students also put the most value on American English.

For the solidarity dimension, on the other hand, the students highly evaluated the nativized varieties (Japanese and Chinese English) rather than the native variety (American English), and Chinese English was evaluated the highest. Given that the students were Japanese, Japanese English was expected to be valued the most, but the results turned out to be different from the expectation. Regarding this, Takahashi (2012) indicates that 'they might not want to consider themselves too strongly as speakers of Japanese English at the same time' (p.32), which reflects the Japanese students' complex and ambivalent mindset for Japanese English.

Concerning the perception of their own variety by Chinese EFL learners, Kirkpatrick and $\mathrm{Xu}$ (2002) conducted empirical research to investigate Chinese college students' attitudes toward 'China English'. The result represents "the majority felt it was unlikely that there could be a Chinese variety of English and they did not want to sound Chinese when they spoke English" (p.277). On the other 
hand, however, $\mathrm{He}$ and $\mathrm{Li}$ (2009) reported that "the attitudes of mainland Chinese learners and teachers of English seem to be shifting toward accepting 'China English' as a legitimate, indigenized variety" (p.86) in their study. Furthermore, Yang (2010) stresses that Chinese college students show positive attitudes toward 'China English' and no longer see the English variety as a disadvantage. Yang associates the result with the recent globalization in China that brings many opportunities for Chinese college students to get exposed to cross-cultural communication. They can notice that it is natural for non-native English speakers to use their own varieties, which is nothing to be embarrassed about.

\subsection{Introducing EIL in EFL Education}

Although the viewpoint of English varieties has started to change recently, EFL learners' perception of their own varieties is negative across the board. In the given situation, English as an International Language (EIL) is expected to be an instrument for introducing a pluralistic view of English varieties into EFL learners' mindset and improve their negative stereotypes and attitudes toward nativized varieties including their own varieties. EIL was put forth by Smith (1976), redefining the role of 'English as an International Auxiliary Language' (EIAL) that is 'used by people of different nations to communicate with one another' (p.38). Smith (1976) stresses that because English does not belong to any countries and cultures, people do not have to mimic the culture and identity of the native speakers but express their own culture and identity in English. Similarly, Baker (2011) contends the importance of English learning is not to learn the native speaker's culture but to develop 'intercultural awareness' for intercultural communication. Further, all the varieties are equal based on the idea of EIL. In relation to it, Sharifian (2009) and Marlina (2014) certify that any particular variety should not be selected as the medium of international and intercultural communication. Therefore, the negative impacts from 'Standard English' such as English imperialism, linguicism, and native-speakerism (Holliday, 2006) do not stand there. Hence, EIL can facilitate EFL learners to have a positive mindset for English varieties, reflect their culture and identity in English, and understand different English varieties showing respect for the speakers' cultures and identities.

Further, Smith (1976) claims ownership for all English users no matter whether they are native or non-native English speakers; "It is yours (no matter who you are) as much as it is mine (no matter who I am)" (p. 39). From the perspective of EIL, therefore, everyone can acquire ownership of English. In the context of EFL education in the expanding circle countries (e.g., South Korea, Japan, and China; Kachru, 1992), wide acceptance of English ownership to include 'non-native' speakers is expected to positively affect some aspects of EFL education. For instance, Nakamura (2002) reported that "the majority of the students (Japanese EFL learners) involved in this EIL global education demonstrate a positive response to this program and many students developed confidence in EIL speech communication" (p.72). In light of the theory of Smith (1976) and the report of Nakamura (2002), the concept of EIL has great potential to play an important role in enhancing L2 learners' confidence.

Regarding the methodology for putting the concept of EIL into practice, some researchers implemented empirical research projects that approach the learners' perception of EIL. For instance, Lee et al. (2017) implemented a videoconferencing-embedded classroom (VEC) that is an instructional instrument to raise the learner's perception toward EIL. The VEC is comprised of three different stages: 1) pre-videoconference task (11 weeks), 2) during-videoconference task (2 weeks), and 3) postvideoconference task ( 1 week). In the pre-VT, students read EIL-related articles and discussed the content through presentations for the preparation of the during-VT where they discussed the topic and interacted with EIL scholars from the three-circle countries (USA, Hong Kong, South Korea, and Indonesia). In the final stage, the post-VT, the students wrote a reflective essay and gave a presentation based on the essay content. Looking at the time allocation in each stage, it is likely that the pre-VT is a very critical stage (11 weeks) where the students read the book English in Japan in the era of globalization (Seargeant, 2011). Such finding indicates that 'input' (in this case, the readings) is a key process to raise the EIL perception.

In our previous study (Saito, Heo \& Perkins, 2020), we conducted empirical research to investigate how EIL would affect Japanese EFL learners' attitudes toward English varieties and enhance their L2 speaking confidence. The design of this study was similar to that of the study of Lee et al. (2017) in terms of the process to introduce the idea of EIL into a class activity, except for the part that the communication with the international (Chinese and Vietnamese) students was held face-to-face not 
online. Although there was no clear EIL involvement in improving the participants' actual L2 speaking confidence self-report, the Japanese participants showed positive attitudes toward nativized varieties, including Japanese English, in the post-survey. The result indicated that the idea of EIL potentially can lead to enhanced L2 speaking confidence in the long run.

\subsection{This Study}

In this study, we report on factors influencing EIL education in EFL classes regarding the perception and attitudes toward nativized varieties of English by EFL learners. Previous research findings showed that the EIL study and intercultural discussions with Chinese/Vietnamese conversation partners contributed to the positive attitude toward their own English by Japanese EFL learners enrolled in a college EFL class. In this research, we compare the post-survey of the Japanese students with that of international (Chinese and Vietnamese) students who participated in the same activity not as students registered in the course but as conversation partners (interlocutors) for the activity. By further investigating the factors influencing the attitudes of the student group and the interlocutor group, we report on the involvement of those factors in EIL education. The present study aims to answer the following research questions:

(1) Would EFL learners' knowledge on EIL or World Englishes affect their attitudes toward nativized varieties of English?

(2) How do attitudes toward nativized varieties of English differ among Japanese, Chinese and Vietnamese participants after the intercultural EIL activities implemented in the Japanese EFL class?

(3) What influences the difference in the attitudes toward nativized varieties between different expanding circle groups?

\section{METHODOLOGY}

\subsection{Participants}

The participants in this study were Japanese, Chinese, and Vietnamese college students majoring in computer science and engineering in Japan. Twenty-six junior and senior Japanese students (24 males and two females), and six Chinese (three males and three females), and six Vietnamese (six males) students participated. The Japanese participants' English proficiency ranged from novice to lowintermediate (the average of their TOEIC score was 380). In contrast, the English proficiency of Chinese and Vietnamese participants ranged from pre-advanced to advanced. Since the university requires international students to have a high level of English capability and complete their degree with the English-only program, their English proficiency was higher than that of the Japanese students. Whereas, the university does not require international students to show Japanese capability for the entrance, so most Chinese and Vietnamese participants were not fluent in Japanese.

\subsection{Materials}

The following materials were used as the participants' pre-activity reading assignments and post-activity reflective writing assignments in the current study.

\section{Reading Materials}

Two types of reading materials (four articles of each type) were prepared: general vs. EILrelated reading. Table 1 below presents the list of reading materials provided before each session. 
Table 1. Reading Materials: Control vs. Experimental

\begin{tabular}{lll}
\hline & Control (General English topics) & Experimental (EIL topics) \\
\hline Reading 1 & Accents in English & English in the world \\
Reading 2 & Why you should study English pronunciation & Ownership of English \\
Reading 3 & Why Japanese have trouble learning English & Japanese English \\
Reading 4 & AI machine translation & Future of Japanese English \\
\hline
\end{tabular}

As shown in the table above, four articles related to general English and EIL were provided for the control group and experimental, respectively. The four topics selected for the experimental group consisted of readings 1) introducing World Englishes (EIL), 2) encouraging non-native speakers of English to use their own English more confidently rather than as something that is "borrowed," 3) some linguistic features and unique expressions of Japanese English, which students are encouraged to use more frequently in their English conversation, and 4) the future direction of Japanese English as one of the recognized varieties of English. None of the four readings selected for the control group was about EIL. The topics covered some general English-related topics such as 1) different varieties of English (native varieties), 2) the importance of learning the "correct" English pronunciation, 3) some difficulties that Japanese speakers face in learning English, and 4) the future of EFL education with the technological advancement in the field of AI machine translation.

\section{Reflection Sheet}

A reflection sheet was prepared to examine the participants' attitudes toward English varieties. The participants answered the following question to indicate whether they agree or disagree with the idea of EIL, including the reasons.

Question:

Do you think non-native speakers should learn and use 'Standard English?' Or do you think it is better to accept the 'English' spoken in non-English speaking countries (i.e., Japan, China, and Vietnam) as legitimate English so that people can learn and use their own English (Japanese English, Chinese English, and Vietnamese English)?

\subsection{Procedures}

The participants were divided into two groups: the control group vs. the experimental group. Half of the participants from each country (13 Japanese, three Chinese and three Vietnamese) are assigned to each group. The exchange activity was conducted four times over two weeks, and each session consisted of the three stages as follows for both the control and the experimental group.

Three-stage Activity

(1) Stage 1: Reading

The participants read an article and work on comprehension quizzes about the article before the session. The theme and content of the material and the comprehension quizzes are different between the control and experimental groups; the control group goes through the general English topics whereas the experimental group does the readings of EIL-related topics.

(2) Stage 2: Group Discussion

The participants discuss the assigned topic questions about the theme and content of the material in a small group. Each group is formed with three members. At least one of them is a Chinese or 
Vietnamese student to realize the expanding circle communication where the participants can get exposed to different English varieties.

(3) Stage 3: Presentation

The participants give a presentation to show their summary of the topic questions and share their group ideas with other small group members, all of whom went through the same topic questions. The presentation is implemented separately in different classrooms between the control and experimental groups so that the participants in the control group do not get influenced by the concept of EIL.

During the discussion session, Chinese and Vietnamese students with the higher English proficiency level took the role of moderator as well as the discussant. Before participating in the discussion activity, they were informed about this role in this activity. They encouraged Japanese participants to express their opinions in simple English as much as possible.

\section{Reflective Writing}

The participants' attitudes toward English varieties were examined with the qualitative research method after having completed four sessions. As shown in the previous section, the reflection sheet was utilized to collect the data. The Japanese participants were asked to provide their opinions and ideas about the question in 300 characters or more in their native language (Japanese) to better grasp their attitudes toward English varieties. On the other hand, the Chinese and Vietnamese participants were asked to write 200 words in English.

\section{JAPANESE EFL LEARNERS' ATTITUDES TOWARD ENGLISH VARIETIES}

\subsection{Results of Reflective Writing}

Eighteen Japanese participants (Control Group: 10, Experimental Group: 8) reflected their ideas and opinions about 'Standard English' and their perception of nativized varieties (Japanese, Chinese, and Vietnamese English). Most of the Japanese participants in the control group (eight out of 10) disagreed with the idea of EIL and showed negative attitudes toward nativized varieties. Many of the participants indicated the importance of English as a common communication tool among various people with various linguistic and cultural backgrounds. According to them, English would not bring a clear understanding of people's ideas and opinions if the language reflects each speaker's culture and identity. Some of their actual answers are provided below. Their original answers in Japanese are translated below into English.

Japanese student A:

I disagree with the idea. We should learn 'Standard English'. This is because the main reason why we learn English is that English is a common communication tool by which people can communicate with anyone from any country. Therefore, including diversity in the language might bring an obstacle to understanding people's ideas and opinions.

Japanese student B:

I disagree with the idea. I suppose that non-native English speakers should learn 'Standard English' and use it. As for the reason, we will have more chances to communicate with various people as globalization is progressive. [...] If we officially acknowledge the value of non-native English, it will be hard to communicate due to the unique accents and ways of speaking.

Japanese student $C$ :

I agree with the idea, more or less. Although communication will be harder when we accept the varieties of English, each country's English is sort of its identity with the local culture and language, so it is questionable to unify all English as the same language.

Unlike the participants in the control group, all of Japanese participants in the experimental group (eight out of eight) agreed with the idea of EIL and showed positive attitudes toward nativized varieties. The following are the parts of their comments mentioning their opinions on EIL and nativized varieties. 
Japanese student D:

I agree with the idea. I'm not confident in my English because I try to mimic 'Standard English', that is, to use correct English. Because of that, I feel it is difficult for me to discuss with other countries' people. On the other hand, I can learn about other countries cultures and identities through their English based on the idea.

Japanese student E:

I agree with the idea. In line with the development of globalism, the recognition that English is a world common language has been stronger. On the other hand, the value of other languages will get lower, and these languages start disappearing. [...] Therefore, the idea is very important in order to keep the original culture and identity through their own English.

Japanese student $F$ :

I agree with the idea. Since I was told to speak English like a native English speaker in school, I thought that we should speak American English before the discussion. However, I started considering that there is no drawback in 'Japanese English', and we should respect our own culture and reflect it in our English as a Japanese. [...] I think that Japanese people should express themselves to the world in their own English, and it will bring the connections with other countries' people, which leads to the development of the global society.

\subsection{Analysis and Discussion}

Most of the Japanese EFL learners in the control group (eight out of 10), whose reading materials were general English topics not EIL, negatively evaluated nativized varieties, including their own (Japanese English) and argued the importance of teaching 'Standard English.' The result is consistent with the report of Takahashi (2012). Although nativized varieties are more familiar than native varieties for the Japanese students, their complex and ambivalent attitudes interrupt them from being fully positive about Japanese English. For that, Takahashi argues the importance of improving Japanese EFL learners' complex and ambivalent attitudes toward nativized varieties, especially toward Japanese English, and stresses the importance of integrating a pluralistic view of English varieties.

On the contrary, the experimental-group students (eight out of eight), who read EIL-related articles before discussion, positively viewed nativized varieties through EIL readings and discussions. With the role of EIL that brings the equal status value of all English varieties, it is conceivable that EIL promoted the Japanese participants' positive attitudes toward 'Japanese English,' an English variety that they are most familiar with. Thus, EIL can be one of the powerful instruments to change and improve EFL learners' stereotypes and attitudes toward nativized varieties, especially their own English varieties.

\section{CHINESE AND VIETNAMESE EFL LEARNERS' ATTITUDES TOWARD ENGLISH VARIETIES}

\subsection{Results of Reflective Writing}

Five Chinese and four Vietnamese participants (Control Group: 4, Experimental Group: 5) also reflected their ideas and opinions about the exchange activity and World Englishes. Most of the participants (seven out of nine) disagreed with the idea of EIL. Furthermore, only one participant in the experimental group (one out of five) positively viewed EIL. Given that all the Japanese participants (eight out of eight) in the experimental group showed a positive attitude toward nativized varieties, the result of the Chinese and Vietnamese participants turned out to be completely different. Further, the main reason why they preferred native varieties to nativized varieties is very similar to the one from the Japanese participants in the control group. English is an international language used to communicate with people from other countries, so they believe we should learn and use 'Standard English' to facilitate successful and efficient communication. First, the comments of the participants in the control group are shown as follows. 
Chinese student A:

From my point of view, it is better for non-native speakers to learn and use 'Standard English' rather than accept English spoken in non-English speaking countries. First, 'Standard English' can make people understand each other more easily. [...] If people use their own 'special' English, there is a big chance that they won't be able to understand each other. [...] In my opinion, language is just a tool to get information.

Chinese student B:

I think learning 'Standard English' is a good thing because English is an international language that needs a unified standard. Without it, each English might develop differently from generation to generation, and people might have difficulty in communicating in English. [...] Therefore, 'Standard English' is quite important.

Vietnamese student A:

I think there is no 'Standard English.' Who has such power to decide which English is standard? [...] Language is just a thing to communicate with others. As long as the language helps people understand each other, it is successfully doing its job. [...] However, people try to pronounce English like how high-class people pronounce, that is, the US and UK people do. In Vietnam, it is obvious since our country is small and poor, and people want to show their power by speaking English in the way of the US and UK people.

Vietnamese student $B$ :

In my opinion, non-native speakers had better study and get accustomed to 'Standard English.' [...] If people from non-English speaking countries develop their own English, it can be easy for them to communicate with one another. Still, it is very hard to communicate with 'Standard English' speakers.

Then, the participants' comments in the experimental group, which are not largely different from the control group, are provided below.

\section{Chinese student D:}

I totally agree with the idea even though I want to speak like native speakers. [...] if people stop talking just because of their 'incorrect' pronunciation and their negative impression of the pronunciation, it is a pity.

Chinese student E:

I think people should try to speak 'Standard English' because we use English to communicate with foreign people with different native languages. If they don't know about our native language and cultural background, it will be difficult for them to understand our special English, which reflects our native culture.

Chinese student $F$ :

I disagree with the ideas of EIL. [...] English is the common language of the world. English can connect our nations together. If we all learn native English, it will be more convenient and efficient for people in our different countries to communicate with each other. But, if we speak our own English such as Japanese, Chinese, and Vietnamese English, rather than mimicking 'Standard English', then we lose the true meaning of learning English, successful and efficient communication between people in different countries.

Vietnamese student D:

I disagree with the idea of EIL for some reasons. To begin with, English is a universal language, a convenient means of communication, education, business, and so on because of its popularity. By studying 'Standard English,' we are capable of exploring the world outside our country with minimal effort.

Vietnamese student E:

While I do agree with this idea to a certain extent, I also believe it has some downsides. [...] The idea of EIL not only will make learning English much more pleasant for non-native speakers but also will encourage cultural diversity in our society. However, the idea has some drawbacks as well. [...] Taking the local culture also means the loss of the international context of the language. At 
some point, a version of English might become a language that cannot be understood by people outside of the community.

\subsection{Analysis and Discussion}

As mentioned in the analysis and discussion of the Japanese students' reflection sheets, the reason why the Japanese participants in the experimental group followed the idea of EIL seems to be the positive encouragement they received from the four EIL readings to recognize and actively use their own English variety in the internationalized world where many different Englishes are spoken. This is related to solidarity; nativized varieties are more familiar than native varieties. In the result of Chinese and Vietnamese participants, on the other hand, the aspect of solidarity for nativized varieties cannot be found in the comments from the Chinese and Vietnamese participants even in the experimental group.

In other studies on Chinese EFL learners' perception of 'China English' (He \& Li, 2002; Yang, 2010), it was generally assessed that EFL learners' stereotypes and attitudes toward nativized varieties have been gradually changed and improved in line with the development of globalization. This is because that the borderless communication environment provides more opportunities to communicate with people world-widely and encourages the exposure and usage of various English varieties. Taking into account these previous studies and the backgrounds, it was expected that more participants in the experimental group would agree with the idea of EIL and show positive attitudes toward nativized varieties, but the result went against the expectation.

The reason for the unexpected result can be associated with the intercultural communication environment and context. There is a difference between the current study and the previous studies in terms of the environment and context; the participants (Chinese and Vietnamese) in the current study are international students in Japan, while those (Chinese) in the previous studies ( $\mathrm{He} \& \mathrm{Li}, 2002$; Yang, 2010) are domestic students. Looking first at the case of international students in Japan, they communicate with Japanese students and faculty members at the university, and the local people outside the campus. In this setting, it is very significant for them to communicate with the Japanese accurately and smoothly for their successful academic and daily life in Japan. In the academic context, for instance, international students possibly fail if they miscommunicate about important things such as course assignments and exams with Japanese students and instructors. Consequently, the participants prioritize native varieties over nativized varieties since obtaining precise information is more important than seeing the cultural aspects through intercultural communication in English varieties for them. Additionally, it is supposed that the participants have experienced miscommunication in English with Japanese students at the university due to the gap in English proficiency. Related to this, Yang (2010) reported that the majority of Chinese students think 'China English' is acceptable, as long as it is comprehensible. Though the students accept nativized varieties, the comment implies that the students would not accept the varieties including 'China English' if they have difficulty in communicating with people. In light of the point, the risk and fear of miscommunication can also affect the participants to prefer native varieties to nativized varieties and disagree with the idea of EIL.

On the contrary, domestic students do not have to be anxious and stressed about the miscommunication with international students and faculty members. This is because international students and faculty members are mostly expected to fulfill English or the local language requirements to study or teach at college, so it is supposed to be rare that domestic students face serious miscommunication with them. Even though there is a miscommunication between them because of their English varieties, the international students and faculty members have enough English or the local language capability and cross-cultural communicative competence to fix it so that domestic students can understand them properly. Hence, domestic students do not have to stick with 'Standard English' and can enjoy English varieties, including their own variety, through multicultural communication with the international students and faculty members, which makes them accept nativized varieties and agree with the idea of EIL. 


\section{CONCLUSIONS}

In this study, we analyzed the post-survey result of the short-term intercultural communication between Japanese and Chinese/Vietnamese students. In comparing two groups whose pre-activity reading materials were EIL-related topics (experimental group) and general English topics (control group), the results differed for different language groups. For the Japanese participants, there was a clear difference in their attitudes toward nativized varieties between the control and the experimental group; the Japanese participants who did the EIL reading showed positive attitudes toward the nativized varieties including their own (Japanese English) while the Japanese participants in the control group still exhibited a strong preference toward 'Standard English' (native varieties). However, such impact of EIL-reading was not found for the Chinese or Vietnamese participants; there was no difference in the result for the control (general English readings) and the experimental group (EIL readings). Most of the international participants showed negative attitudes toward nativized varieties, emphasizing the importance of learning 'Standard English.'

Based on the result, we can conclude that there are two main factors influencing EFL learners' attitudes toward nativized varieties (e.g., Japanese, Chinese, and Vietnamese English): EIL knowledge (EIL readings) and EFL environment. The EFL environment can be further broken down into individual factors such as English proficiency and locality. In the case of the Japanese EFL learners who communicated with international students with a higher English level at their home ground, the knowledge on EIL (EIL readings in the experimental group) could nurture positive attitudes toward nativized English varieties, including their own English. In the case of the Chinese and Vietnamese learners, on the other hand, learning about EIL was not followed by a positive perception of nativized English varieties. This perception results from the difficulty they experienced when they communicated with Japanese EFL students with lower English proficiency in the EFL class of a foreign country. Most of the Chinese and Vietnamese participants disagreed with the idea of EIL. They showed negative attitudes toward nativized varieties, claiming the importance of 'Standard English' as a common communication tool among people with various linguistic and cultural backgrounds. Yet, as shown in the result of Japanese EFL learners, EIL education can change the negative attitudes toward their own English, facilitating the improvement in L2 confidence. Namely, EIL helps EFL learners to reconsider their stereotypes and attitudes toward English varieties and encourages them to be positive about nativized varieties, especially their own English varieties, which brings them the high L2 confidence and performance. Certainly, there are still many challenges and issues that need to be resolved in order to introduce EIL into EFL education and create the design as an EFL teaching/learning methodology. Still, this study will further proceed so that it can be a stepping stone to embody the idea in the future.

\section{References}

Baker, W. (2011). Intercultural awareness: Modelling an understanding of cultures in intercultural communication through English as a lingua franca. Language and Intercultural Communication, 11(3), 197-214.

Bolton, K. (2004). World Englishes. In A. Davies and C. Elder (eds.), The handbook of applied linguistics (pp. 367-396). Oxford, England: Blackwell.

Brutt-Griffler, J. (2004). World English a study of its development. Clevedon: Multilingual Matters.

Crystal, D. (2003). English as a global language, 2nd edition. Cambridge: Cambridge University Press.

Gatcho, A. R., \& B. Ramos, Jr., E. T. (2019). Stylistic Analysis of Philippine English and Singaporean English in Automotive Review Articles. International Journal of Language and Literary Studies, 1(1), 1-13. https://doi.org/10.36892/ijlls.v1i1.23

Görlach, M. (1997). Language and nation: The concept of linguistic identity in the history of English. English World-Wide, 18(1), 1-34. doi:10.1075/eww.18.1.02gor

Griffee, D. T. (1997). Validating a questionnaire on confidence in speaking English as a foreign language. JALT Journal 19(2), 177-197. 


\section{Factors Influencing EFL Learners' Attitudes toward English Varieties}

Hanamoto, H. (2008). The language attitudes toward English varieties of Japanese learners. Proceedings of the 22nd Annual Conference of The Japanese Association of Sociolinguistic Sciences, 90-93.

Hanamoto, H. (2010). How do the stereotypes about varieties of English relate to language attitude?: A quantitative and qualitative study of Japanese university students. The Japanese Journal of Language in Society, 12(2), 18-38.

He, D., \& Li, D. C. (2009). Language attitudes and linguistic features in the 'China English' debate1. World Englishes, 28(1), 70-89. doi:10.1111/j.1467-971x.2008.01570.x

Holliday, A. (2006). Native-speakerism. ELT Journal, 60(4), 385-387.

Jenkins, J. (2006). Current perspectives on teaching World Englishes and English as a lingua franca. TESOL Quarterly, 40(1), 157-181.

Jenkins, J. (2009). World Englishes. New York: Routledge.

Kachru, B. B. (1985). Standards, codification and sociolinguistic realism: The English language in the Outer Circle. In R. Quirk and H. G. Widdowson (eds.), English in the world: Teaching and learning the language and literatures (pp. 11-30). Cambridge: Cambridge University Press.

Kachru, B. B. (1992). The other tongue: English across cultures. Urbana: University of Illinois Press.

Kirkpatrick, A. (2007). World Englishes: Implications for international communication and English language teaching. Cambridge: Cambridge Univ Press.

Kirkpatrick, A., \& Zhichang, X. (2002). Chinese pragmatic norms and 'China English'. World Englishes, 21(2), 269-279. doi:10.1111/1467-971x.00247

Lee, J. S., Nakamura, Y., \& Sadler, R. (2017). Effects of videoconference-embedded classrooms (VEC) on learners' perceptions toward English as an international language (EIL). ReCALL, 30(3), 319336. doi: $10.1017 / \mathrm{s} 095834401700026 \mathrm{x}$

Marlina, R. (2014). The pedagogy of English as an international language (EIL): More reflections and dialogues. In R. Marlina, \& R.A. Giri (Eds.), The pedagogy of English as an international language: Perspectives from scholars, teachers, and students (pp. 1-19), (Vol. 1). Springer.

Matsuda, A. (2000). Japanese attitudes toward English: A case study of high school students. Unpublished doctoral dissertation, Purdue University, West Lafayette, Indiana.

Matsuda, A. (2003). The ownership of English in Japanese secondary schools. World Englishes, 22, 483-496.

Matsuda, A. (2009). Desirable but not necessary? The place of world Englishes and English as an international language in English teacher preparation programs in Japan. In F. Sharifian (Ed.), English as an international language: Perspectives and pedagogical issues (pp.169-189). Bristol: Multilingual Matters.

McArthur, T. (1998) The English Languages, Cambridge: Cambridge University Press.

McArthur, T. (2002) The Oxford Guide to World Englishes, Oxford: Oxford University Press.

McKay, S. L. (2002). Teaching English as an international language: Rethinking goals and perspectives. New York: Oxford University Press.

McKay, S. L. (2003a). Toward an appropriate EIL pedagogy: Re - examining common ELT assumptions. International journal of applied linguistics, 13(1), 1-22.

McKay, S.L. (2012). Principles of teaching English as an international language. In L. Alsagoff, S. L. McKay, G. Hu, \& W. A. Renandya (Eds.), Principles and practices for teaching English as an international language, (pp. 28- 46). New York: Routledge.

McKenzie, M. (2004). Attitudes of Japanese nationals towards standard and non-standard varieties of Scottish English speech. The East Asian Learner (formerly The Japanese Learner), 1, 16-25. 
Nakamura, K. (2002). Cultivating global literacy through English as an International Language (EIL) education in Japan: A new paradigm for global education. International Education Journal, 3, 6474.

Takahashi, M. (2012). Language Attitudes of Japanese University Students toward Japanese English. Proceedings of the 41st Annual Meeting of the English Language Education Society of Japan, 27-34. Institute for Digital Enhancement of Cognitive Development, Waseda University.

Rajadurai, J. (2005). Revisiting the concentric circles: Conceptual and sociolinguistic considerations. Asian EFL Journal, 7(4), 111-130.

Rose, H., \& Montakantiwong, A. (2018). A tale of two teachers: A duoethnography of the realistic and idealistic successes and failures of teaching English as an international language. RELC Journal, 49(1), 88-101.

Saito, A., Heo, Y., \& Perkins, J. (2020). Building Confidence in L2 Speaking through the Expanding Circle Communication: Practicing English as an International Language (EIL). Journal of Language Sciences, 27(2), 199-228.

Saud, M. S. (2020). Teaching English as an international Language (EIL) in Nepal. Indonesian TESOL Journal, 2(1), 29-41. doi:10.24256/itj.v2i1.1079

Seargeant, P. (2011). Introduction: English in Japan in the era of globalization. English in Japan in the Era of Globalization, 1-12. doi:10.1057/9780230306196_1

Sharifian, F. (2009). Cultural conceptualizations in English as an international language. In F. Sharifian (Ed.), English as an international language, (pp. 242-253). Brostol: Multilingual Matters.

Sharifian, F. (2009). English as an international language: An overview. In F. Sharifian (Ed.), English as an international language, (pp. 1-18). Brostol: Multilingual Matters.

Sharifian, F. (2014). Teaching English as an International Language in Multicultural Contexts: Focus on Australia. In R. Marlina, \& R.A. Giri (Eds.), The pedagogy of English as an international language: Perspectives from scholars, teachers, and students (pp. 35-46), (Vol. 1). Springer.

Smith, L. E. (1976). English as an International Auxiliary Language. RELC Journal, 7(2), 38-42. doi:10.1177/003368827600700205

White, R. (1997) 'Going Round in Circles: English as an International Language, and Crosscultural Capability' Paper prepared for the Cross-Cultural Capability Conference '97, Leeds Metropolitan University, 15-16 December 1997.

Yamanaka, N. (2006). An evaluation of English textbooks in Japan from the viewpoint of nations in the Inner, Outer, Expanding circles. JALT Journal, 28, 57-76.

Yang, Y. (2010). Attitudes of learners toward English: A case of Chinese college students. Graduate Program in Education, The Ohio State University.

Yoshikawa, H. (2005). Recognition of world Englishes: changes in Chukyo University students' attitude. World Englishes, 24(3), 351-360.

Zacharias, N. T. (2014). Integrating EIL pedagogy in a pre-service teacher education program. TEFLIN Journal, 25(2), 217-232.

\section{AUTHORS'BIO}

Arifumi Saito is an English lecturer at the University of Aizu in Japan. He is interested in English as an International Language (EIL) and has introduced the idea in the university EFL classes. In line with the research, he has also investigated the Japanese and international students' attitudes toward English varieties. 